\title{
APLIKASI MAQASID ASY-SYARI'AH PADA SISTEM KEUANGAN SYARIAH
}

\author{
Muhammad Zaki \\ Dosen Sekolah Tinggi Agama Islam (STAI) \\ Yasni Muara Bungo, Jambi \\ e-mail:mdzakiismail@gmail.com \\ Bayu Tri Cahya \\ Dosen Sekolah Tinggi Agama Islam Negeri (STAIN) \\ Kudus, Jawa Tengah \\ e-mail:bayu_plur@yahoo.com
}

\begin{abstract}
Abstrak
Maqa>s\}id asy-shari>'ah is relevant koredor as a basis for the development of the system, practice, and sharia banking products. The order of maqa>sjid asy-shari>'ah is the way the light for the journey of sharia banking in answer the question dynamic based on the common good and welfare. The concept of Islamic economy is a prerequisite that must be developed further, not only in the conceptual overtones teapi also in practical overtones, especially in the practice of sharia banking. Islam has been providing textual sources that adequate to provide limitations prioritising man, but it is not enough if not balanced with social inferensi. The theory maqa>s\}id asy-shari>'ah in the study of the Islamic economy is a step forward in the development of Islamic economic model that most ideal. This is because the maqa>s\}id asyshari>'ah can be used as the tool to help resolve the argument in specify a law in order to achieve the goal of shortening the law.
\end{abstract}

Keywords: Maqa>s\}id asy-shari>'ah, sharia economy, mas\}is\}ah.

\section{A. Pendahuluan}

Perkembangan ekonomi dan bisnis syari'ah dewasa ini terlihat semakin pesat khususnya di Indonesia. Hal ini terbukti dengan berdirinya beberapa lembaga syari'ah, seperti perbankan syari'ah, asuransi syari'ah, pasar modal syari'ah, reksadana syari'ah, baitul ma>l wa at-tamwi $>l$, koperasi syari'ah, pegadaian syari'ah dan lain-lain. Ekonomi dan bisnis syari'ah ini tidak hanya dalam bentuk lembaga-lembaga bank maupun non-bank, 
akan tetapi juga meliputi aspek-aspek perekonomian yang lebih luas, seperti ekonomi makro dan mikro dan masalah-masalah ekonomi lainnya.

Secara ekonomis, perbankan syari'ah dikembangkan sebagai solusi atas ketidakmampuan sistem ekonomi ribawi selama ini dalam menghadapi permasalahan ekonomi yang semakin banyak dan kompleks. Lebih dari itu, tujuan utama dari sistem perbankan syari'ah adalah untuk mencapai dan mewujudkan kesejahteraan umat secara luas dunia dan akhirat. Dengan mengacu pada tujuan utama ini, maka maqa>s\}id asysyari>'ah menjadi sandaran utama dalam setiap pengembangan operasional dan produk-produk yang ada di bank syariah.

Para ulama ushul fikih sepakat bahwa pengetahuan maqa>s\}id asy-syari>'ah menjadi syarat utama dalam berijtihad untuk menjawab berbagai problematika kehidupan ekonomi dan keuangan yang terus berkembang. Maqa>s\}id asy-syari>'ah tidak saja diperlukan untuk merumuskan kebijakan-kebijakan ekonomi makro (moneter, fiskal, public finance), tetapi juga untuk menciptakan produk-produk perbankan dan keuangan syariah serta teori-teori ekonomi mikro lainnya. Selain itu maqa $>$ s\}id asy-syari>'ah juga sangat diperlukan dalam membuat regulasi perbankan dan lembaga keuangan syari'ah.

Maqa>s\}id asy-syari>'ah tidak saja menjadi faktor yang paling menentukan dalam melahirkan produk-produk ekonomi syari'ah yang dapat berperan ganda sebagai alat sosial kontrol dan rekayasa socio-economy untuk mewujudkan kemaslahatan manusia, tetapi lebih dari itu, maqa>s\}id asy-syari>'ah dapat memberikan dimensi filosofis dan rasional terhadap produkproduk hukum ekonomi syariah yang dilahirkan dalam aktivitas ijtihad ekonomi syari'ah kontemporer. Maqa>s\}id asy-syari>'ah akan memberikan pola pemikiran yang rasional dan substansial dalam memandang akad-akad dan produk-produk perbankan syariah. Sedangkan pemikiran fikih semata akan menimbulkan pola pemikiran yang formalistik dan tekstualis. Hanya dengan pendekatan maqa>s\}id asy-syari>'ah-lah produk perbankan dan keuangan syariah dapat berkembang dengan baik dan dapat merespon kemajuan bisnis yang terus berubah dengan cepat. 


\section{B. Definisi dan Dasar Penetapan Maqa>s\}id asy-Syari>'ah}

Maqa>s\}id asy-syari>'ah (مقاصد الثريعة) terdiri dari dua kata yaitu maqa>s\}id dan asy-syari>'ah yang hubungan antara satu dan lainnya dalam bentuk $i d$ ) $a>f a h$ (mud $a>f$ dan $m u d\} a>f u n$ ilaihi). Kata maqa>s\}id adalah adalah jamak dari kata maqs\}ad ( مقصد), (Munawwir' 1997 : 1124) yang artinya adalah maksud dan tujuan (Syarifuddin, 2008 : 231). Kata asy-syari>'ah (الشريعة) yang sejatinya berarti hukum Allah swt., baik yang ditetapkan sendiri oleh Allah swt., maupun ditetapkan Nabi sebagai penjelasan atas hukum yang ditetapkan Allah swt. atau dihasilkan oleh mujtahid berdasarkan apa yang ditetapkan oleh Allah swt. atau dijelaskan oleh Nabi (Syarifuddin, 2008 : 231). Definsi lain dari syariah adalah segala hukum dan aturan yang ditetapkan Allah swt. bagi hamba-Nya untuk diikuti, yang mengatur hubungan antara manusia dengan Allah swt., hubungan antara manusia dengan manusia, dan hubungan antara manusia dengan lingkungan dan kehidupannya (Fahurrahman, 2013 : 31).

Berdasarkan arti dari kedua kata tersebut, maka istilah maqa>s\}id asy-syari>'ah memiliki makna sebagai apa yang dimaksud oleh Allah swt. dalam menetapkan hukum, apa yang dituju oleh Allah swt. dalam menetapkan hukum atau apa yang ingin dicapai oleh Allah swt. dalam menetapkan suatu hukum (Syarifuddin, 2008 : 231). Pendapat lain mendefinisikan maqa>s\} id asy-syari>'ah sebagai maksud atau tujuan disyariatkan hukum Islam (Djamil, 2013 : 63).

Dalam kajian ilmu Ushul Fiqh, maqa>s\}id asy-syari>'ah mengandung arti yang sama dengan kata al-h\}ikmah (الحكمة), yang memiliki makna tujuan yang dimaksud Allah swt. dalam penetapan suatu hukum (Syarifuddin, 2008 : 231). Dengan kesamaan arti ini maka Ibnu 'A $<$ shu $>$ r mendefinisikan maqa $>$ s\}id asy-syari>'ah sebagai makna-makna lebih mendalam dan aspekaspek baik dari kebijaksanaan (hikam), yang dipertimbangkan oleh pembuat hukum (Allah swt.) menyangkut semua atau sebagian besar bidang dan keadaan dalam pembuatan hukum (Isra, 2015 : 200). Sedangkan Riya $>d\}$ Mans\}u $>$ r al-Khali $>$ fi $>$ dalam tulisannya mendefinisikan maqa>s\}id asy-syari>'ah sebagai makna-makna dan hikmah-hikmah yang diinginkan pembuat syariat (Allah swt.) dalam penetapan hukum untuk kemaslahatan makhluk-Nya di dunia dan akherat (Riyad, 2004 : 
8). Dalam tulisan ini penulis cenderung mendefinisikan maqa>s\} id asy-syari>'ah sebagai maksud serta hikmah yang ingin dicapai oleh Allah swt. dalam menetapkan suatu hukum atau aturan demi tercapainya kemaslahatan bagi seluruh makhluk-Nya, baik di dunia maupun akherat.

Pada dasarnya, tujuan utama syariah adalah mengatur kehidupan manusia dan melindungi kepentingan dan manfaat (maslah\}ah) orang-orang. Dalam konteks dan perspektif Islam, maslah\}ah berarti apa yang baik bermanfaat di mata syariah (Isra, 2015 : 200). Berdasarkan tujuan utama syariah ini, maka timbulnya pemikiran tentang maqa>s\}id asy-syari>'ah dapat diperkirakan beriringan dengan pemikiran tentang dalil syara' dan penggunaannya. Kebiasaan mujtahid dalam menghadapi suatu kasus yang muncul selalu mencari petunjuk dari Alquran dari segala seginya. Bila mereka tidak menemukan, maka mereka mencari jawaban dalam sunnah Nabi dari segala cara. Ketika para mujtahid tidak menemukan petunjuk dari keduanya, maka mereka mencoba meneladani cara yang dilakukan Allah swt. dalam menentukan hukum, yaitu dimana ditemukan maslah\}ah, maka berlakulah hukum Allah swt. Padanya (Syarifuddin, 2008 :246).

\section{Maslah\}ah sebagai Dasar Maqa>s\}id asy-Syari>'ah}

Maslah\}ah secara etimologi berarti sesuatu yang baik, dirasakan lezat, oleh karenanya menimbulkan kesenangan dan kepuasan serta diterima oleh akal yang sehat. Amir Syarifuddin dalam bukunya Ushul Figh menjelaskan bahwa tujuan Allah swt. dalam menetapkan hukum adalah untuk memberikan kemaslahatan kepada umat manusia dalam kehidupannya di dunia, maupun dalam persiapannya menghadapi kehidupan akherat. Oleh karena itu, beliau menyatakan bahwa maqa>s\} id asy-syari>'ah adalah maslah\}ah itu sendiri(Syarifuddin, 2008 : 232).

Dari segi tujuan yang hendak dicapai, maslah\}ah dibagi dalam dua kelompok, yaitu (Syarifuddin, 2008 : 233):

1. Mendatangkan manfaat kepada umat manusia, baik bermanfaat untuk hidup di dunia maupun akherat.

2. Menghindarkan kemudaratan (bahaya) dalam kehidupan manusia, baik kemudaratan di dunia maupun akherat. 
Dari segi apa yang menjadi sasaran atau ruang lingkup yang dipelihara dalam penetapan hukum, maka maslah\} ah dibagi menjadi lima, yaitu (Syarifuddin, 2008 : 233238):

1. Memelihara agama atau keagamaan (حفظ الدين)

2. Memelihara jiwa atau diri atau kehidupan (حفظ لنظ (حف) (حف) (حف)

3. Memelihara akal (حفظ العقل)

4. Memelihara keturunan (حفظ النسل)

5. Memelihara harta (حفظ المال)

Kelima hal di atas disebut oleh al-Ghazali sebagai lima maqa>słid asy-syari>'ah. Dari segi tingkat kepentingan memeliharanya, maslah\}ah yang menjadi bagian dari maqa>s\}id asy-syari>'ah terbagi kepada tiga tingkatan, yaitu (Syarifuddin, 2008 : 239-240):

1. Tingkat primer (الضروريات) yaitu sesuatu yang sangat perlu dipelihara atau diperhatikan, seandainya tidak atau terabaikan akan membawa kepada tidak ada atau tidak berartinya kehidupan.

2. Tingkat sekunder (الحاجيات) yaitu suatu kebutuhan untuk memeliharanya, namun bila tidak dipelihara tidak membawa pada hancurnya kehidupan, tetapi hanya menimbulkan kesulitan atau kekurangan dalam melaksanakannya.

3. Tingkat tertier (التحسينيات) yaitu sesuatu yang sebaiknya dilakukan untuk mengambil manfaat dan sebaiknya ditinggalkan untuk menghindari kemudaratan.

Muhammad Ayub dalam bukunya Understanding Islamic Finance, memaparkan bahwa secara keseluruhan tujuan di balik syariat Allah swt. adalah kebahagian dan kesejahteraan manusia di dunia dan akherat, dan semua hal yang menjamin kesejahteraan dan memenuhi kepeningan utama dari uma manusia tercakup dalam tujuan-tujuan syariah (maqa>s\}id asy-syari>'ah) (Ayub, 2009 : 34). Tujuan-tujuan tersebut dapat dibagi dalam dua kelompok, yaitu:

1. Tujuan Primer

Tujuan primer yang ingin diwujudkan oleh syariah adalah perlindungan dan pemeliharaan atas (Ayub, 2009 :35): 
Aplikasi Maqa<S\}Id Asy-Syari<'Ah Pada Sistem Keuangan ...
a) Agama.
b) Kehidupan.
c) Keturunan - anggota keluarga.
d) Harta.
e) Intelek.
f) Kehormatan.

2. Tujuan Sekunder

Tujuan primer syariah akan membawa ke beberapa tujuan sekunder yang terdiri atas (Ayub, 2009:36):

a) Penegakan keadilan dan kesamaan dalam masyarakat.

b) Peningkatan keamanan sosial, sikap saling membantu, dan solidaritas, khususnya untuk membantu yang miskin serta membutuhkan dalam memenuhi kebutuhan dasar mereka.

c) Pemeliharaan kedamaian dan keamanan.

d) Peningkatan kerjasama dalam hal kebaikan dan larangan perbuatan serta tindakan jahat.

e) Peningkatan nilai moral universal yang utama dan semua tindakan yang perlu untuk pemeliharaan dan penguasaan alam.

\section{Pembangunan Ekonomi Berbasis Maqa>słid asy-Syari>'ah}

Masuknya teori maqa>s\}id asy-syari>'ah ke dalam wilayah ekonomi Islam dapat ditemukan langsung dalam landasan etika. Para pelaku ekonomi tidak hanya dituntut untuk dapat menguasai sumber-sumber ekonomi yang strategis tetapi juga memanfaatkannya untuk kepentingan umat dengan mengacu pada kemaslahatan primer, sekunder, maupun tertier. Dengan demikian, bagi kajian ekonomi Islam, maqa>s\}id asy-syari>'ah adalah salah satu usaha logis yang wajib diterapkan sebagai konsekuensi dari pemahaman ekonomi yang berkeadilan di satu sisi dan berketuhanan di sisi lain.

Indikator-indikator pembangunan ekonomi yang didasarkan pada maqâshid syari'ah menurut 'Abdul Mun'im Afar sebagaimana dikutip oleh Ali Rama dan Makhlani dapat dilihat dari (Ali Rama dan Makhlani, 2013, 31-46):

1. Pemeliharaan Agama Jika pokok-pokok ibadah seperti mengucapkan kalimat 
syahadat, pelaksanaan sholat, zakat, haji d an lainlain, adalah sebagai indikator $\mathrm{b}$ agi terpeliharanya keberadaan agama, maka s egala s esuatu yang mutlak dibutuhkan -baik materil maupun non materil, s arana barang dan jasa- untuk melaksanakan ibadah tersebut harus tersedia dan terealisasi terlebih dahulu. Kebutuhan dasar tersebut antara lain merujuk pada identifikasi kebutuhan berupa sarana, barang dan jasa sebagai berikut:

a. Untuk menjaga kesinambungan iman dan akidah maka setidaknya perlu disediakan antara lain: jasa da'i dan pembimbing ibadah, pencetakan dan penerbitan buku-buku agama termasuk Alquran dan Hadis, pendirian pusat-pusat pengajian dan bimbingan agama.

b. Untuk melaksanakan ibadah yang terdiri dari:

1) Sholat, dibutuhkan mesjid dan musholla, jasa imam $\mathrm{d}$ an muadzin, d ana-dana waqaf untuk biaya pemeliharaan tempat ibadah, dan penyediaan fasilitas-fasilitas penunjang lainnya.

2) Zakat, dibutuhkan pembentukan struktur k elembagaan zakat yang terintegrasi $\mathrm{d}$ an d ikelola secara profesional dan transparan, pelatihan manajemen pengumpulan, pengelolaan dan distribusi zakat, pemetaan potensi pengumpulan dana zakat dari para muzakki dan pemetaan sebaran mustahiq zakat, penegakan hukum bagi pihak yang tidak mau membayar zakat, pembentukan lembaga yang intens mensosialisasikan kewajiban membayar zakat serta hukum-hukum agamnya.

3) Puasa, dibutuhkan lembaga pendidikan yang mengajarkan hukum-hukum puasa, penciptaan lingkungan yang mendukung lancarnya pelaksanaan puasa, menyemarakkan kegiataan keagamaan selama bulan Ramadhan.

4) Haji, diperlukan pembentukan lembaga pengelolaan pelaksanaan haji dan lembaga pengelola dana haji, penyediaan alat transportasi dan penginapan yang nyaman dan lembaga 
bimbingan haji dan pengajaran manasik haji.

5) Lembaga peradilan, dibutuhkan jasa kepemimpinan kepala negara, majelis permusyawaratan, para hakim, lembaga urusan Islam.

6) Lembaga keamanan: jasa aparat keamanan untuk menjaga keselamatan para pelaksana dakwah, keamanan masyarakat dan negara dan memberikan hukuman bagi para pelanggar aturanaturan yang berlaku.

2. Pemeliharaan Jiwa dan Akal

Kebutuhan akan pemeliharaan jiwa dan akal meliputi makan dan minum, berpakaian dan bertempat tinggal (kebutuhan akan rumah). Artinya kebutuhan akan pangan, sandang dan papan adalah mutlak harus terpenuhi untuk menjaga jiwa dan akal manusia, agar dapat menjaga eksistensi hidup serta menjalankan fungsi utamanya sebagai pelaku utama pembangunan (khalifah). Terpenuhinya kebutuhan dasar tersebut adalah merupakan hak dasar dari setiap individu. Pembangunan ekonomi harus menempatkan pemenuhan kebutuhan dasar setiap individu sebagai prioritas utama, karena jika tidak terpenuhi akan mengancam eksistensi hidup manusia (jiwa). Pemeliharaan keselamatan jiwa meliputi sembilan bidang pokok:

a. Makanan pokok dan perlengkapan penyajiannya, lauk-pauk beserta bumbu- bumbu, air bersih dan garam.

b. Perangkat perlengkapan untuk pemeliharaan badan.

c. Pakaian.

d. Perumahan

e. Pemeliharaan kesehatan dengan ketersediaan rumah sakit, peralatan sakit, obat-obat, dokter, ambulans, dan lain-lain.

f. Transportasi dan telekomunikasi berupa alat transportasi darat, laut dan udara dan alat-alat komunikasi.

g. Jasa keamanan bagi individu dan masyarakat.

h. Lapangan yang halal dan manusiawi, upah yang 
adil, dan kondisi kerja yang nyaman.

i. Lembaga perlindungan sosial seperi pemeliharaan lanjut usia, anak yatim piatu, bantuan bagi para penganggur dan jaminan sosial.

Sedangkan pemeliharaan akal dapat terdiri dari:

a. Pendidikan: p enyediaan lembaga pendidikan dari tingkat dasar sampai perguruan tinggi, biaya pendidikan yang rendah bahkan gratis, penyediaan alokasi dana yang tinggi untuk sektor pendidikan, penyediaan sarana pendidikan yang memadai termasuk guru dan tenaga pengajar.

b. Penerangan dan kebudayaan

c. Penelitian ilmiah: pusat pengembangan kurikulum, pusat pengembangan ilmu modern, pusat penelitian, dan lain-lain.

3. Pemeliharaan Keturunan dan Harta

Tidak ada peradaban yang mampu bertahan jika generasi mudanya memiliki kualitas spiritual, fisik dan mental yang rendah, sehingga berdampak pada ketidakmampuan untuk menghadapi tantangan kehidupan yang semakin dinamis. Oleh kerenanya mesti dilakukan perbaikan secara terencana dan berkelanjutan untuk memperbaiki kualitas generasi muda. Salah satu langkah untuk memperbaiki karakter dan keperibadian mereka adalah dengan menanamkan akhlak baik (khuluq hasan) melalui proses tarbiyah di keluarga dan lembaga pendidikan.

Sementara harta merupakan fasilitas yang dianugerahkan Allah swt. kepada manusia untuk menunjang fungsi utamanya sebagai khalîfah di bumi. Harta adalah amanah yang harus dikembangkan secara terencana untuk tujuan menghilangkan kemiskinan, memenuhi kebutuhan dasar setiap individu, membuat kehidupan terasan nyaman dan mendorong terciptanya distribusi pendapatan dan kekayaan yang merata. Dalam memperoleh $\mathrm{d}$ an mengembangkan harta dituntut untuk didasarkan pada nilai-nilai Islam. Harus ada filter moral 
dalam pengelolaannya.

Untuk menjaga keselamatan keturunan dan harta maka dibutuhkan lembaga-lembaga yang terkait dengan:

a. Pemeliharaan keturunan

1) Lembaga pernikahan yang akan mempermudah legalitas pernikahan, $p$ embelakan $p$ rapernikahan, pembinaan rumah tangga paska pernikahan, dan lain-lain.

2) Pusat pembinaan ibu-ibu berkenaan dengan kesehatan, psikologi, dan makanan, pemeriksaan rutin untul memastikan kesehatan dan keselamatan janin.

3) Pemeliharaan anak-anak: bimbingan $d$ an pendidikan kesehatan bagi anak-anak, lembaga pengasuhan anak, program dasar untuk kesehatan dan nutrisi anak, penanaman akidah yang benar dan prinsip-prinsip dasar agama Islam, memberikan bekal keahlian bagi anak-anak kurang mampu.

4) Yayasan anak yatim sebagai pusat pemeliharaan anak-anak yatim.

5) Pembentukan lembaga pemeliharaan harta.

6) Pembentukan lembaga keuangan dan investasi.

7) Strategi keuangan akurat untuk pembangunan dan pemeliharaan harta.

8) Pengamanan pemeliharaan $h$ arta dengan penerapan $\mathrm{huku}$ man atas pencuri, perampas harta dan pelaku kecurangan, pelarangan riba, sogok dan korupsi.

9) Menjamin keamanan harta dan kepemilikan pribadi, pengaturan aka-akad transaksi seperti jual beli, perkongsian, sewa, dan lain-lain.

10) Pengajaran berkenaan dengan tata cara mendapatkan harta dan pengembangannya, sumber-sumber pendapatan halal dan haram, hukum-hukum transaksi, dan lain- lain.

Berdasarkan u raian d i atas, maka konsep k ebutuhan $\mathrm{d}$ asar yang harus menjadi prioritas pembangunan ekonomi adalah segala kebutuhan dasar minimal yang harus ada 
dan diperlukan untuk menjaga keselamatan agama, jiwa, kekuatan jasmani, akal dan harta manusia, agar setiap individu dapat melaksanakan kewajiban terhadap diri sendiri, keluarga, masyarakat, sistem sosial dan keamanan; kebutuhan yang dimaksud mencakup segala macam barang dan jasa primer, sebagai sarana yang harus dihasilkan dalam proses pembangunan dengan perencanaan yang tepat disertai anggaran yang memadai.

Oleh karenanya, pembangunan berbasis maqa $>$ s\}id asy-syari>'ah adalah pembangunan yang meletakkan prioritas utamanya untuk memenuhi kebutuhan dasar manusia demi terpeliharanya lima maslahat pokok (agama, akal, jiwa, keturunan dan harta) melalui usaha dalam proses produksi atau pembangunan ekonomi. Terpenuhinya kebutuhan dasar setiap individu akan berkorelasi pada peningkatan kesejahteraan atau tercipta kesejahteraan. S ebaliknya, apabila manusia tidak mampu memenuhi kebutuhan dasarnya, ia akan merasakan ketidakpuasan, tidak damai, tidak senang, tidak bahagia, tidak aman. Kondisi ini adalah kondisi tidak sejahtera.

Dengan demikian terdapat hubungan antara pembangunan ekonomi yang berbasis maqa>s\}id asy-syari>'ah dengan pemenuhan kebutuhan dasar hidup manusia, dan juga hubungannya dengan kondisi kesejahteraan, yang bila disimpulkan bahwa pembangunan ekonomi yang memprioritaskan pemenuhan kebutuhan dasar manusia adalah merupakan predisposisi dari kesejahteraan, dalam arti kesejahteraan sosial akan ditentukan oleh bagaimana masyarakat dapat memenuhi kebutuhan dasar.

\section{E. Aplikasi Maqa>słid asy-Syari>'ah dalam Sistem Keuangan Syariah}

Menurut Abdul Wahab Khalaf, eksistensi maqa>s\}id asy-syari>'ah menjadi penting karena ia dapat dijadikan sebagai alat bantu dalam memahami redaksi Alquran dan sunnah, membantu menyelesaikan dalil yang saling bertentangan dan yang sangat penting lagi adalah untuk menetapkan suatu hukum dalam sebuah kasus yang ketentuan hukumnya tidak tercantum dalam Alquran dan sunnah jika menggunakan kajian semantik (kebahasaan). 
Disinilah pentingnya maqa>s\}id asy-syari>'ah dalam praktek ekonomi dan keuangan kekinian, di tengah ketidaksamaan praktek perbankan syariah di berbagai negara (Fathurrahman, $2014:$ 212).

Selama ini, dominasi fikih klasik sebagai landasan operasional keuangan dan perbankan Islam sangat nyata dan fakta. Padahal fikih hanyalah sekedar hasil rasionalisasi kreatif ulama yang hidup pada zamannya. Sebagai contoh, berbagai produk transaksi yang ditawarkan perbankan syariah sebagai lokomotif gerakan ekonomi Islam, dimana hampir semuanya merujuk pada jenis-jenis transaksi konrak dalam fikih klasik. Di sisi lain, penyusunan bangunan keilmuan ekonomi Islam banyak diadopsi dari teori-teori ekonomi konvensional dengan melakukan sedikit penyesuaian. Akibatnya, apa yang disebut dengan ekonomi Islam tidak lebih dari kumpulan teori ekonomi konvensional plus fikih saja. Untuk itu perlu kiranya rekontekstualisasi fikih, agar tetap bisa seirama dengan perjalanan dinamika zaman yang selalu melahirkan banyak persoalan yang berbeda satu sama lain, termasuk permasalahan terkait dengan sistem keuangan Islam.

Berkaitan dengan hal tersebut, maqa>s\}id asy-syari>'ah merupakan koredor yang relevan sebagai dasar pengembangan sistem, praktek, bahkan produk perbankan syariah di era multidemensi sekarang. Tatanan maqa>s\}id asy-syari>'ah dinilai oleh mayoritas ulama sebagai jalan terang bagi perjalanan perbankan syariah dalam menjawab persoalan dinamis, karena berdasarkan pada kemaslahatan dan kesejahteraan. Konsep maslah\}ah merupakan tujuan utama dari ditetapkannnya hukum Islam.

Berikut contoh peninjauan produk-produk dan operasional di bank syariah pada umumnya dan di Bank Muamalat pada khususnya dengan nilai-nilai maqa $>$ s\} id asy-syari>'ah (http://elsimh-feb11.web.unair.ac.id/ artikel):

1. Terjaga agama para nasabah. Hal ini diwujudkan dengan Bank Muamalat menggunakan Alquran, hadis, 
dan hukum Islam lainnya sebagai pedoman dalam menjalankan segala sistem operasional dan produknya. Dengan adanya Dewan Pengawas Syariah (DPS) dan Dewan Syariah Nasional (DSN), membuat keabsahan bank tersebut dalam nilai-nilai dan aturan Islam semakin terjamin dan Insya Allah dapat dipercaya oleh kalangan muslim dan non-muslim.

2. Terjaga jiwa para nasabah. Hal ini terwujud dari akadakad yang diterapkan dalam setiap transaksi di bank syariah. Secara psikologis dan sosiologis penggunaan akad-akad antar pihak menuntun manusia untuk saling menghargai dan menjaga amanah yang diberikan. Di sinilah nilai jiwanya. Selain itu, hal ini juga terwujud dari pihak stakeholder dan stockholder bank syariah dimana dalam menghadapi nasabah dituntut untuk berperilaku, berpakaian, dan berkomunikasi secara sopan dan Islami.

3. Terjaga akal pikiran nasabah dan pihak bank. Hal ini terwujud dari adanya tuntutan bahwa pihak bank harus selalu mengungkapkan secara detail mengenai sistem produknya dan dilarang untuk menutup-nutupi barang sedikit pun. Di sini terlihat bahwa nasabah diajak untuk berpikir bersama ketika melakukan transaksi di bank tersebut tanpa ada yang dizalimi oleh pihak bank. Bank syariah ikut memintarkan nasabah (adanya edukasi di setiap produk bank kepada nasabah).

4. Terjaga hartanya. Hal ini terwujud jelas dalam setiap produk-produk yang dikeluarkan oleh bank dimana bank berupaya untuk menjaga dan mengalokasikan dana nasabah dengan baik dan halal serta diperbolehkan untuk mengambil profit yang wajar. Selain itu, terlihat juga dari adanya penerapan sistem zakat yang bertujuan untuk membersihkan harta nasabah secara transparan dan bersama-sama.

5. Terjaga keturunannya. Hal ini terwujud dengan terjaganya empat hal di atas, maka dana nasabah yang Insya Allah dijamin halal akan berdampak baik bagi keluarga dan keturunan yang dinafkahi dari dana tabungannya tersebut. 
Aplikasi Maqa<S\}Id Asy-Syari<'Ah Pada Sistem Keuangan ...

\section{F. Penutup}

Konsep ekonomi Islam adalah suatu keniscayaan yang harus dikembangkan lebih jauh, tidak hanya dalam tataran konseptual teapi juga dalam tataran praktis, khususnya praktek di perbankan syariah. Islam telah menyediakan sumber-sumber tekstual yang memadai untuk memberikan batasan prilaku manusia, namun hal itu tidak cukup jika tidak diimbangi dengan inferensi sosial. Adanya teori maqa>s\}id asy-syari>'ah dalam kajian perekonomian Islam merupakan langkah maju dalam pengembangan model ekonomi Islam yang paling ideal. Hal ini karena maqa $>$ s\}id asy-syari>'ah dapat dijadikan alat bantu dalam membantu menyelesaikan dalil dalam menetapkan suatu hukum dalam rangka mencapai tujuan disyariatkannya hukum tersebut. 


\section{DAFTAR PUSTAKA}

Ayub, Muhammad. Understanding Islamic Finance: A-Z Keuangan Syariah. Jakarta: Gramedia Pustaka Utama, 2009.

al-Azhari, Mus\}t\}afa Mah\}mud. Taisir Qawa'id an-Nah\}wi lil Mubtadi'in. Mis\}ra: Maktabah al-'Ulum wa al-H\}ikam, 2011.

Babisti, 'Azizah Fawal. al-Mu'jam al-Mufas\}s\}il fi an-Nahwi al'A rabi. Beirut: Da>r al-Kutub al-'Ilmiyyah, 1992.

al-Badwi, Yusuf Ah\}mad Muhłammad. Maqas\}id asy-syari'ah 'inda Ibn Taimiyah. al-Urdun: Dar an-Nafa' is, t.t.

Djamil, Fahurrahman. Hukum Ekonomi Islam: Sejarah, Teori dan Konsep. Jakarta: Sinar Grafika, 2013.

Fathurrahman, Ayif. "Pendekatan Maqasid asy-Syari'ah: Konstruksi Terhadap Pengembangan Ilmu Ekonomi dan Keuangan Islam". Hunafa: Jurnal Studia Islamika, Vol. 11, No. 2, Desember 2014.

ISRA. Sistem Keuangan Islam: Prinsip dan Operasi. Jakarta: Rajawali Pers, 2015.

al-Khalifi, Riyad\} Mans\}ur. "al-Maqas\}id asy-Syari'ah wa Asaruha fi Fiqhi al-Mu'amalat al-Maliyah". Majallah Jami'ah al-Malik 'Abdul 'Aziz: al-Iqtisad al-Islami, Vol. 17, No. 1, Tahun, 2004.

Lahsasna, Ahcene. Maqasid asy-Syari'ah in Islamic Finance. Kuala Lumpur: IFBIM, 2013.

Munawwir, Ahmad Warson. Kamus Arab-Indonesia Terlengkap. Surabaya: Pustaka Progressif, 1997. 
Aplikasi Maqa<S\}Id Asy-Syari<'Ah Pada Sistem Keuangan ...

Rama, Ali dan Makhlani. "Pembangunan Ekonomi dalam Tinjauan Maqasid Syaria'ah". Dialog: Jurnal Penelitian dan Kajian Keagamaan. Vol. 1, No. 1, Juni 2013.

asy-Syatibi, Abu Ish\}aq Ibrahim ibn Musa ibn Muh\}ammad alLakhmi. al-Muwafaqat. al-Mamlakah as-Sa'udiyyah al'Arabiyyah: Dar 'Affan, cet. 2, 1997.

Syarifuddin, Amir. Ushul Figh. Jakarta: Prenada, cet. IV, Jilid. 2, 2008. 